\title{
ARTICLE
}

\section{Acute and transient psychoses: clinical and nosological issues}

\author{
Augusto Castagnini \& Gian Maria Galeazzi
}

Augusto Castagnini studied medicine and psychiatry, and earned a PhD from the University of Cambridge (UK) for a dissertation on reactive psychoses. His research conducted at the Danish Centre for Psychiatric Research in Risskov contributed to challenging current classification of acute and transient psychoses. Gian Maria Galeazzi is Associate Professor of Psychiatry at the University of Modena and Reggio Emilia. He has worked as a psychiatrist in Italy, Germany, Australia and the UK. His main research interests are in social psychiatry and consultation liaison psychiatry. Correspondence $\mathrm{Dr}$ Augusto C. Castagnini, School of Child Neuropsychiatry, University of Modena and Reggio Emilia, Modena, Italy. Email: augusto. castagnini@unimore.it

\begin{abstract}
SUMMARY
This article examines the clinical, epidemiological and nosological aspects of short-lived psychotic disorders as currently classified under 'acute and transient psychotic disorders' in ICD-10 and 'brief psychotic disorder' in DSM-5. After describing earlier diagnostic concepts such as bouffée délirante, cycloid psychosis, reactive psychosis and schizophreniform psychosis, we present an overview of the literature and discuss implications for classification, diagnosis and treatment of these conditions, pointing out differences from longerlasting psychotic disorders.
\end{abstract}

\section{LEARNING OBJECTIVES}

- Appreciate the different ways in which acute and transient psychoses have been conceptualised historically and recognise how these relate to current nosologies

- Identify clinical and epidemiological features of acute and transient psychoses and differentiate them from organic psychosis, schizophreniaspectrum disorders and affective disorders on the basis of ICD-10 and DSM-5 criteria

- Recognise the increased risk of premature mortality, particularly suicide, associated with acute and transient psychoses, and the difficulty in treating these varied conditions

\section{DECLARATION OF INTEREST}

None

Ever since Kraepelin introduced in 1896 the nosological dichotomy between dementia praecox (later renamed schizophrenia) and manicdepressive psychosis (i.e. bipolar disorder), efforts to delineate intermediate categories have been made in different psychiatric traditions (Wimmer 1916; Kleist 1928; Kasanin 1933; Langfeldt 1939; Leonhard 1957), but the evidence drawn on proved inconclusive. This has caused difficulties in classification and nomenclature, mainly for transient psychotic disorders that do not involve prominent affective features, and concealed Kurt Schneider's (1959) basic question - namely, 'whether [in such cases] a psychic reaction or a psychosis is present'.
In this article we outline early categories of European psychiatry and describe how acute and transient psychoses have been incorporated and differentiated from schizophrenia and affective disorders in current psychiatric nosography, such as ICD-10 (World Health Organization 1992) and DSM-5 (American Psychiatric Association 2013). We then present empirical data and discuss implications for classification, diagnosis and treatment of these conditions. We leave aside transient psychotic disorders subsumed under the heading of the so-called 'culture-bound syndromes', and other intermediate categories such as schizoaffective psychosis.

\section{Early views}

\section{Bouffée délirante}

The French concept of bouffée délirante was developed by Magnan (1887) and followers (Legrain and Saury) in the wake of the late 19th-century theory of degeneration. They distinguished transient delusional states characterised by sudden onset and fleeting polymorphic features (délire d'emblée) from more persistent and uniform delusional disorders leading to mental deterioration (délire chronique à évolution systématique).

This description has striking similarities to Ey's (1954) category of 'acute delusional psychosis' based on his 'organo-dynamic' theory and listed in the French classification of mental disorders (Garrabé 2012). To improve diagnostic reliability, French psychiatrists (Pull 1987) formulated explicit criteria for bouffée délirante, such as: (a) abrupt onset; (b) polymorphic delusions, emotional changes, mood swings, depersonalisation, derealisation and/or hallucinations; (c) complete remission within weeks or a few months; (d) exclusion of organic causation, alcohol and drug misuse; and (e) no psychiatric antecedent except bouffée délirante. Studies of the natural course of bouffée délirante reported varying transition rates to either schizophrenia and related disorders or affective disorders (Weibel 2005). The use of the diagnosis bouffée délirante has decreased since the 1980s, and it is currently included in studies of first-episode psychosis (Garrabé 2012). 


\section{Cycloid psychosis}

Kleist introduced the term zykloide Psychosen (cycloid psychosis) to designate 'phasic illnesses which come and go autochthonously [sic] like manic depression, frequently in dual, contrasting phases of confused excitement and stupor, or hyperkinesis and akinesis, running their course and leaving behind no residual defects' (Kleist 1928: p. 300). Leonhard (1957) added 'anxietyhappiness psychosis', which resulted from the combination of 'anxiety psychosis' and 'revelation psychosis'. In Leonhard's view, cycloid psychosis was different from both schizophrenia and manic depression (now called bipolar disorder), and comprised three clinical forms: anxiety-happiness psychosis, confusion psychosis and motility psychosis, which involved an impairment of affect, thinking and psychomotor activity respectively. In Anglophone psychiatry, Perris \& Brockington (1981) provided operational criteria for diagnosis of cycloid psychosis, such as sudden onset and polymorphic symptoms, which were eventually incorporated into the checklist of the ICD-10 category 'acute and transient psychotic disorders' (ATPDs; World Health Organization 1992).

Cycloid psychosis is prevalent in women and accounts for many cases of post-partum psychosis; antipsychotic medication must be used cautiously owing to elevated risk of neuroleptic syndrome and catatonia (Beckmann 2001). Follow-up studies have shown that cycloid psychosis fares better than schizophrenia in both course and outcome (Leonhard 1957; Jabs 2004). Cutting (1990) claimed that cycloid psychosis conforms more to an atypical variant of affective disorder. Twin and family studies have found that cycloid psychosis has only a modest hereditary basis; there seems to be greater evidence that it arises when complications during pregnancy and at birth affect the early stages of brain development (Beckmann 2001).

\section{Reactive (psychogenic) psychosis}

Drawing on the methodological distinction between 'explanation' and 'understanding', Jaspers (1913) described the concept of reactive psychosis, encompassing clinical conditions with affective, confusional and paranoid features triggered by a psychological trauma. Symptoms in reactive psychosis were meaningfully connected to the extent of the traumatic event, the semantic or symbolic role (i.e. defence, escape, wish fulfilment) and the content. Although of clinical and heuristic value, Jaspers' criteria were criticised for their subjective character (Schneider 1959).
The concept of reactive psychosis was further developed in Scandinavia (Wimmer 1916; Strömgren 1974), but its validity was hampered by follow-up studies showing high transition rates to either schizophrenia or affective disorders (Ungvari 1997). In continental (European) and British psychiatry, diffusion of the diagnosis of reactive psychosis was hindered by strong opposition to the notion of 'psychological causation' and controversies about the separation between reactive and endogenous depression (Lewis 1972). Schneider's (1959) view that all psychoses have a 'somatic' basis was also influential and contributed to the neglect of reactive psychosis in modern psychiatric classifications. The concept of psychological reactivity, on which reactive psychosis was based, has been redefined in terms of stress vulnerability, life events, and social and cultural differences; nowadays interest in psychological trauma tends to concentrate on post-traumatic stress disorder.

\section{Schizophreniform psychosis}

The term 'schizophreniform psychosis' was coined by Langfeldt (1939) to denote schizophrenialike states with rapid remission in response to 'shock treatment'. Acute onset, precipitating stress, mental confusion, affective symptoms and extroversion differentiated this category from schizophrenia. Related conditions are the 'acute schizoaffective psychoses' described by Kasanin (1933) in people presenting with mixed symptoms triggered by stressful events, and Labhardt's (1963) schizophrenieähnlichen Emotionspsychosen (schizophrenia-like emotion psychoses).

In North American psychiatry, research on outcome prediction helped to define the concept of 'good-prognosis schizophrenia' ('remitting schizophrenia') (Vaillant 1962). The DSM has, since its third edition, included the category of 'schizophreniform disorder', characterised by typical schizophrenic symptoms with a duration of 1-6 months. The following 'specifiers' have been added to indicate prognostic factors for schizophreniform disorder that may be associated with a favourable outcome: onset within 4 weeks; confusion or perplexity; good social and occupational functioning; and absence of blunted or flat affect. Yet, the diagnostic criteria for schizophrenia included occupational and social dysfunction and a tendency to a persistent course (at least 6 months).

\section{Current psychiatric classifications}

Influenced by findings of the World Health Organization (WHO) collaborative study on acute 
TABLE 1 Main differences between ICD-10 'acute and transient psychotic disorders' and DSM-5 'brief psychotic disorder'

\begin{tabular}{|lll|}
\hline & $\begin{array}{l}\text { ICD-10 acute and transient } \\
\text { psychotic disorders }\end{array}$ & DSM-5 brief psychotic disorder \\
\hline Symptoms & $\begin{array}{l}\text { Polymorphic, schizophrenic and } \\
\text { predominantly delusional }\end{array}$ & $\begin{array}{l}\text { Delusions, hallucinations, disorganised } \\
\text { speech, grossly disorganised or } \\
\text { catatonic behaviour }\end{array}$ \\
\hline Onset & Acute onset ( $\leq$ 2 weeks) & Not specified \\
\hline Duration & 1 or 3 months & 1 day to less than 1 month \\
\hline Specify if: & with 'acute stress' within 2 weeks & $\begin{array}{l}\text { with 'marked stressor' or onset 'within } \\
\text { 4 weeks post-partum' }\end{array}$ \\
\hline Exclusion & $\begin{array}{l}\text { Substance-induced psychosis, organic } \\
\text { disorders, manic and depressive } \\
\text { episodes }\end{array}$ & $\begin{array}{l}\text { Affective disorder, substance-induced } \\
\text { psychosis, organic disorders, psychotic } \\
\text { disorder not otherwise specified }\end{array}$ \\
\hline
\end{tabular}

psychoses (Cooper 1990), the category of ATPDs (Table 1) appeared in ICD-10 (WHO 1992) within the F2 group 'schizophrenia, schizotypal and delusional disorders'. The ICD-10 stated that: 'The limited data and clinical traditions [...] do not give rise to concepts that can be clearly defined and separated from each other [...]. The nomenclature of these

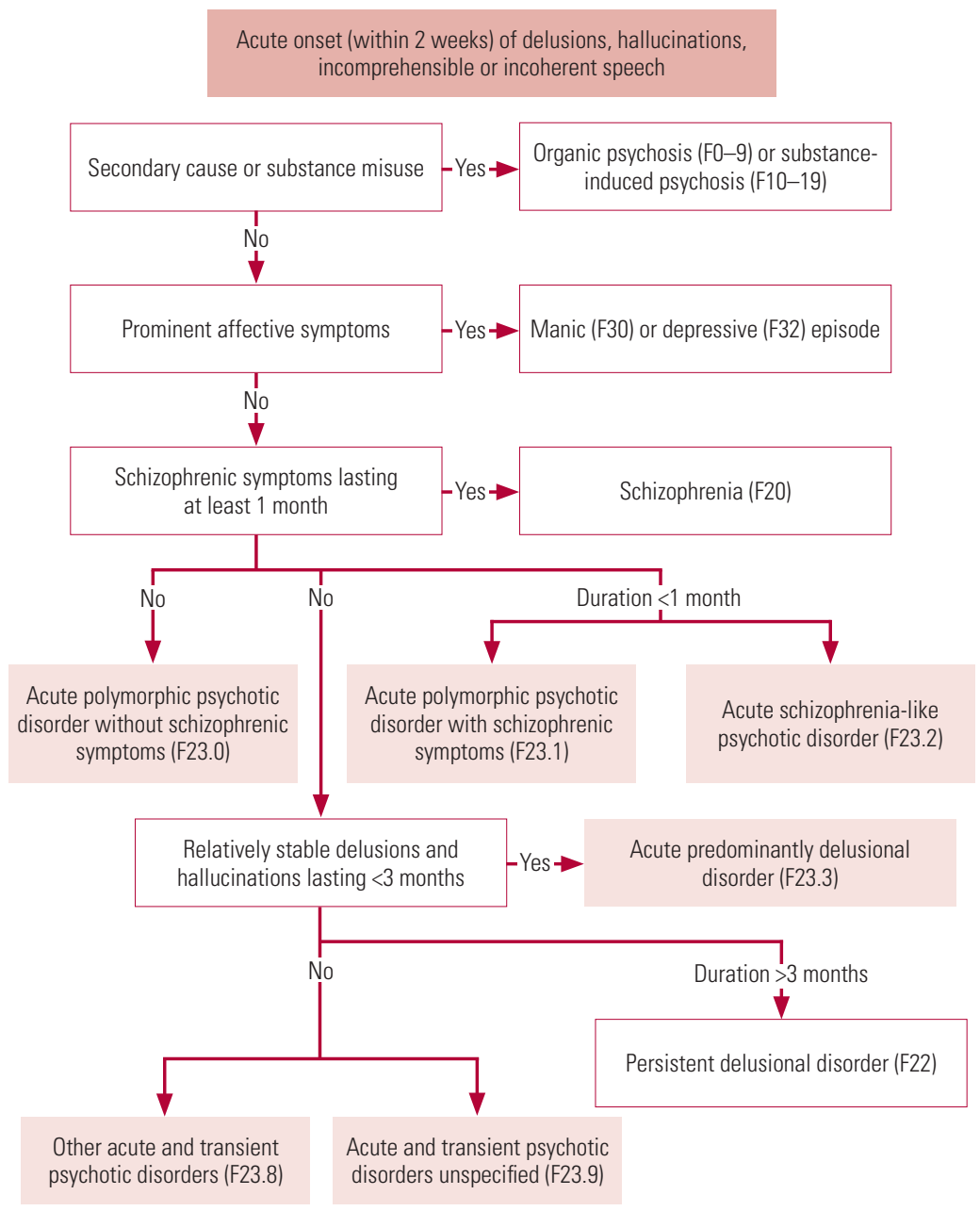

Differential diagnosis of acute and transient psychoses adapted from ICD-10 (World Health Organization 1992). acute disorders is as uncertain as their nosological status' (WHO 1992: pp. 99-100). ATPDs were characterised by: (a) acute onset (within 2 weeks); (b) early remission (complete recovery is expected within 1-3 months); (c) polymorphic, schizophrenic or predominantly delusional syndromes; and (d) association with 'acute stress', regarded as events stressful to most people, such as bereavement, unexpected loss of a partner, job or marriage, or the psychological trauma of combat, terrorism or torture, occurring less than 2 weeks before the onset of psychotic symptoms.

The ATPD category comprises six subtypes: 'acute polymorphic psychotic disorder' (F23.0) refers to bouffée délirante and Kleist's and Leonhard's cycloid psychosis, featuring varied delusions, hallucinations, perceptual changes, perplexity and emotional turmoil (i.e. intense feelings of happiness or ecstasy, or overwhelming anxiety or marked irritability) that shift daily or even more frequently, and can include 'schizophrenic symptoms' (F23.1); 'acute schizophrenia-like psychotic disorder' (F23.2) replaced the ICD-9 category 'acute schizophrenic episode'; 'acute predominantly delusional psychotic disorder' (F23.3) involves relatively stable delusions, usually of persecution or reference, and auditory hallucinations; 'other' and 'unspecified' ATPDs (F23.8-9) are residual classes.

DSM-5 (American Psychiatric Association 2013) listed the category of brief psychotic disorder (Table 1), which features florid psychotic symptoms such as delusions, hallucinations, disorganised speech, and grossly disorganised or catatonic behaviour, lasting less than 1 month. It may follow 'marked stressors' or have its onset in the post-partum period. The diagnostic criteria for schizophreniform disorder are unchanged and symptom duration is intermediate between brief psychotic disorder and schizophrenia.

\section{Differential diagnosis}

The diagnostic criteria for both ATPD and brief psychotic disorder exclude substance-induced psychosis, organic psychosis due to medical conditions, and affective disorders. There may be states of perplexity and inattention, but not so marked or persistent as to suggest delirium, dementia or substance-induced psychosis; in these cases a differential diagnosis is often difficult. To rule out organic causation and substance misuse, a comprehensive clinical assessment, comprising laboratory testing and neuroimaging, is recommended.

The ATPD subtypes (Fig. 1) with schizophrenic symptoms are set apart from schizophrenia by 
temporal criteria of less than 1 month's duration, as the ICD-10 diagnosis of schizophrenia requires duration longer than 1 month; the subtypes characterised by polymorphic and predominantly delusional features last less than 3 months. If delusions last longer, the diagnosis will change to 'persistent delusional disorder' (F22); if only hallucinations persist for more than 3 months, the diagnosis will be 'other non-organic psychotic disorders' (F28).

Differential diagnosis may also involve transient psychotic symptoms in post-traumatic stress disorder, borderline personality disorder, anorexia nervosa and panic attacks.

\section{Concordance between ICD and DSM}

Brief psychotic disorder is an uncommon condition, accounting for just $2-7 \%$ of presentations of firstepisode psychosis (Korver-Nieberg 2011; Nugent 2011; Kingston 2013). Brief psychotic disorder is often a provisional diagnosis (owing to high rates of transition to schizophrenia, schizoaffective disorders or affective disorders) (Nugent 2011; Kingston 2013), but for patients who do not develop longer-term illness, symptoms seem to be less severe than in schizophrenia and outcome for each episode is favourable (Korver-Nieberg 2011).

Comparative studies have reported that ATPD extend beyond the category of brief psychotic disorder (Jørgensen 1997; van der Heijden 2004). Marneros \& Pillmann (2004) found a closer overlap between the two categories, as nearly twothirds of their series of patients with ATPDs met the criteria for brief psychotic disorder.

\section{Epidemiology}

The incidence of ATPDs ranges from 3.9 to 9.8 cases per 100000 population, and the rates for the 2-year and 3-year stable ATPD diagnosis are 6.7 and 1.4 respectively (Singh 2004; Castagnini 2013a). Incidence in males peaks early in their mid-20s, whereas the highest rates for women occur 10 years later and are significantly greater than those for men over 45 years old (Castagnini 2013a). This pattern is likely to reflect not only the putative effect of female sex hormones on the brain, but also diversities across the ATPD subtypes, as polymorphic psychotic disorder is more common in women; cases with acute schizophrenic features predominate in younger men; and acute predominantly delusional disorder has a later age at onset. Reports on the prevalence of ATPDs are also varied, with greater rates in low- and middleincome countries (Esan 2014).

ATPDs have high mortality rates from both natural and unnatural causes (Castagnini 2013b).
The mortality risk is almost twice as high in men, and similar to that for schizophrenia, while there is a small but significant increase in overall and natural-cause mortality compared with bipolar disorder. Suicide is the major cause of premature death and accounts for a quarter of ATPD mortality. Moreover, late-onset ATPDs (over 60 years of age) are associated with a high risk not only of mortality, but also of dementia (Kørner 2009).

\section{Vulnerability factors}

ATPDs are associated with neither specific personality disorders nor premorbid dysfunctions (Jørgensen 1997; Marneros 2004; Singh 2004). In addition, first-degree relatives of patients with ATPDs have higher rates of ATPDs than family members of patients with schizophrenia; yet the risk of schizophrenia is significantly increased in the family of those with schizophrenia (Das 1999).

Further evidence from a large-scale family study (Castagnini 2013c) reveals that the risk of ATPDs was increased in patients with ATPDs who had first-degree relatives not only with ATPDs, but also with bipolar disorder, and particularly with schizophrenia. Only limited support was provided in terms of family predisposition for the different ATPD subtypes. By contrast, the risk of schizophrenia or bipolar disorder was markedly higher in patients with schizophrenia or bipolar disorder who had family members with the same condition. Similar findings were reported by Kanazawa et al (2013), who conducted a genomewide association study of 47 individuals with 'atypical psychosis', a close variant of ATPDs described in Japan (Hatotani 1996), and observed that the putative genes overlapped with those for schizophrenia.

\section{Psychosocial factors}

Psychological and social factors are more likely to be associated with ATPDs in low- and middleincome countries than in high-income ones, where only a relatively small number of cases are triggered by stressful events (Das 2001; Marneros 2004; Singh 2004; Chakraborty 2007; Castagnini 2013d; Esan 2014; Rusaka 2014). Lau et al (2009) found that the risk of ATPDs was two times higher among foreign domestic workers in Hong Kong; homesickness and marital problems were the most common life events. These findings support previous reports showing that refugees and immigrants have a greater risk of psychosis than native populations (Parrett 2010).

Furthermore, life events seem to be more often associated with ATPDs than with schizophrenia 
or manic episodes (Marneros 2004; Chakraborty 2007; Möller 2011), and patients with ATPDs who have a family history of mental disorder tend to have experienced fewer stressful events than those without family psychiatric antecedents (Das 2001). In keeping with the stress-vulnerability model, family predisposition may exert its effects by increasing emotional reactivity, which renders individuals less likely to cope with adverse events.

\section{Diagnostic stability, course and outcome}

A literature review (Castagnini 2011) reported that acute onset, short duration, absence of premorbid dysfunction and female gender were often associated with diagnostic stability and/or favourable outcome in ATPDs. It was also found that individuals with ATPDs fared better than those with schizophrenia, but no sharp distinction between the two categories can be drawn because about half of patients developed longer-lasting psychotic or affective disorders. In low- and middle-income countries, ATPDs seem to have lower rates of recurrence and higher diagnostic stability. Most studies, however, were small and used retrospective data, probably underpowered to produce meaningful findings. Differences in method, study design and distribution of ATPD subtypes also make comparisons difficult.

More recent studies have collected larger samples and mapped the course and outcome of ATPDs in greater detail. For example, Björkenstam et al (2013) identified 1840 patients diagnosed with a first episode of atypical psychosis in the Swedish Psychiatric Register and found that a third of those affected with ATPDs had not been readmitted within 5 years. The risk of conversion to schizophrenia or schizoaffective disorder was twice as high for patients with ATPDs who had first-degree relatives with schizophrenia or bipolar disorder. Such findings compare favourably with a follow-up study by Aadamsoo et al (2011) showing that about half of their patients retained the initial diagnosis of ATPDs, and many had enjoyed stable remission 2 years later. Younger age at onset and longer hospital admission were factors associated with transition to schizophrenia or schizoaffective disorder. Similar findings were reported by Rusaka \& Rancāns (2014) in 294 first admissions with ATPDs followed up for 6 years. They observed that abrupt onset, polymorphic psychotic symptoms and anxiety were more common in those who did not develop another diagnosis. On this point, the McLean-Harvard International First-Episode Project (Salvatore 2011) reported that patients with polymorphic psychotic disorders were less likely than those presenting with acute schizophrenic features to develop schizophrenia or affective psychoses. In keeping with findings of the Münich first-admission psychosis study (Möller 2011), ATPDs have a better long-term outcome than schizophrenia and delusional disorder.

Further evidence (Castagnini 2013d, 2014) suggests that nearly half of 5429 patients first listed in the Danish Psychiatric Register with ATPDs did not change diagnosis over a mean 7.3 years, while in the other half there was a broad pattern of shifts in the first 24 months following the initial episode, mainly to either schizophrenia and related disorders (31\%) or affective disorders (13\%). Although polymorphic psychotic disorder fared better in terms of lower rates of relapse and higher diagnostic stability than the ATPD subtypes with acute schizophrenic or predominantly delusional symptoms, its predictive validity was relatively low.

Lastly, Queirazza et al (2014) selected 2923 first admissions with ATPDs in Scotland and estimated that diagnosis remained unchanged in $54 \%$ of cases on average after 4 years. Schizophrenia was the most common shift and occurred on average 1.7 years later. Duration of first admission over 2 weeks, age under 30 years and male gender predicted increased risk and earlier transition to schizophrenia.

\section{Treatment}

Although patients with ATPDs are usually prescribed antipsychotic medications for acute symptoms and prevention of recurrences, very few clinical trials have addressed the efficacy and safety of treatment (Nugent 2011). The guidelines for first-episode psychosis promote the use of antipsychotics for 1 to 2 years after remission of psychotic symptoms (International Early Psychosis Association Writing Group 2005), and the National Institute for Health and Care Excellence (NICE; 2014) clinical guidelines for psychosis and schizophrenia do not cover transient psychotic disorder. The NICE guidelines recommend psychosocial therapy (i.e. cognitivebehavioural therapy and/or family intervention) for 1 month or less for patients with psychosis who prefer it, then the offer of alternative treatments, including antipsychotics.

In the absence of specific guidance, protracted treatment with antipsychotics needs to be considered cautiously, as several side-effects have been described with both typical and atypical antipsychotics; the latter are also more likely to induce potential adverse effects, such as weight gain and metabolic syndrome, which are associated with increased risk of cardiovascular 
disease, diabetes and premature mortality (Saha 2007). It would appear that the highest naturalcause mortality not only for schizophrenia - where the long-term side-effects of antipsychotics are known to be complicated by behavioural factors such as cigarette smoking, substance misuse, poor diet and a sedentary life-style - but also for ATPDs resulted from cardiovascular and endocrine/ metabolic comorbidities (Castagnini 2013b).

More to the point, a treatment trial involving patients with first-episode psychosis reported that those who discontinued or reduced medication 6 months after symptom remission fared better over the long term than those who remained on maintenance treatment for a further 18 months (Wunderink 2013).

Many individuals with acute psychosis need hospital admission owing to disorganised behaviour, impaired insight, and aggressive and suicidal acts; they require careful risk assessment and a management plan.

\section{Shortcomings of the ATPD category}

\section{ATPDs constitute a composite category}

The ATPDs category includes disparate clinical syndromes with polymorphic, schizophrenic and predominantly delusional features. The ICD-10 field trials (Sartorius 1995) reported that many ATPD subtypes failed to achieve established standards of reliability, probably because of the fleeting nature of 'polymorphic' psychotic symptoms, the inclusion of provisional subtypes separated from schizophrenia only by temporal criteria, and the fact that the vaguely defined acute, predominantly delusional, disorder is a diagnosis by exclusion. In addition, no evidence supports the subdivision of the polymorphic psychotic subtypes into those 'with' and 'without' schizophrenic symptoms on the basis of 1 or 3 months' duration. Only negative symptoms distinguish schizophrenia from ATPDs, as Schneiderian first-rank symptoms of schizophrenia seem to be common to both categories (Marneros 2004; Möller 2011; Salvatore 2011).

\section{ATPDs have little continuity with earlier categories in European psychiatry}

Marneros \& Pillmann (2004) reported that slightly more than half of their series of ATPD cases fulfilled Perris \& Brockington's criteria for cycloid psychosis; yet it was found that cycloid psychosis typically lasts longer than 3 months and only a minority of cases share the ATPD diagnosis (Peralta 2003; van der Heijden 2004). A closer overlap emerged between cycloid psychosis and the polymorphic psychotic subtypes (Marneros
2004), or when cases with prominent affective symptoms were omitted (Peralta 2003). A further study comparing ATPDs with bouffée délirante showed a positive diagnosis in a third of cases for both disorders (Marneros 2004). There also seems to be little continuity between the category of reactive psychosis and ATPDs, owing to changes in the concept of psychosis in modern psychiatric classifications (Castagnini 2009).

\section{ATPDs do not conform to any specific DSM category}

ICD-10 was developed in parallel with DSM-IV, but the ATPD category overlaps only partially with the DSM categories of brief psychotic disorder and schizophreniform disorder, owing to differences in onset, duration and symptomatology.

\section{Stress is an additional diagnostic feature}

A fifth code may be used to indicate whether or not ATPDs are associated with 'acute stress' (F23.x1/0); likewise, the DSM category of brief psychotic disorder may follow 'marked stressors' (it was previously described as 'brief reactive psychosis'). The temporal relationship between stress and ATPDs is limited to 2 weeks, which is probably so restrictive as to have underestimated the number of cases associated with life events. Examination of the 1904-1905 Welsh religious revival revealed a significant increase in hospital admissions for what would now be diagnosed as ATPDs, indicating that transient psychotic disorders may, at least in part, be caused by environmental factors (Linden 2009). These issues raise the need of defining stress more adequately and specifying further its temporal association with illness onset.

\section{The relationship of ATPDs and mood disorders}

Although the ATPD criteria require exclusion of both depressive and manic episodes, emotional changes and affective symptoms may be frequent and transitions tend to occur not only to schizophrenia, but also to affective disorders over the short and longer term (Jørgensen 1997; Marneros 2004; Aadamsoo 2011; Castagnini2013d, 2014; Queirazza 2014; Rusaka 2014). Patients presenting with polymorphic psychotic symptoms are also more likely to develop bipolar disorder than those with schizophrenic or predominantly delusional features, indicating a closer kinship to mood disorders (Marneros 2004; Aadamsoo 2011; Salvatore 2011; Castagnini 2013d, 2014). Genetic epidemiological studies have challenged a sharp demarcation between ATPDs and schizophrenia, 


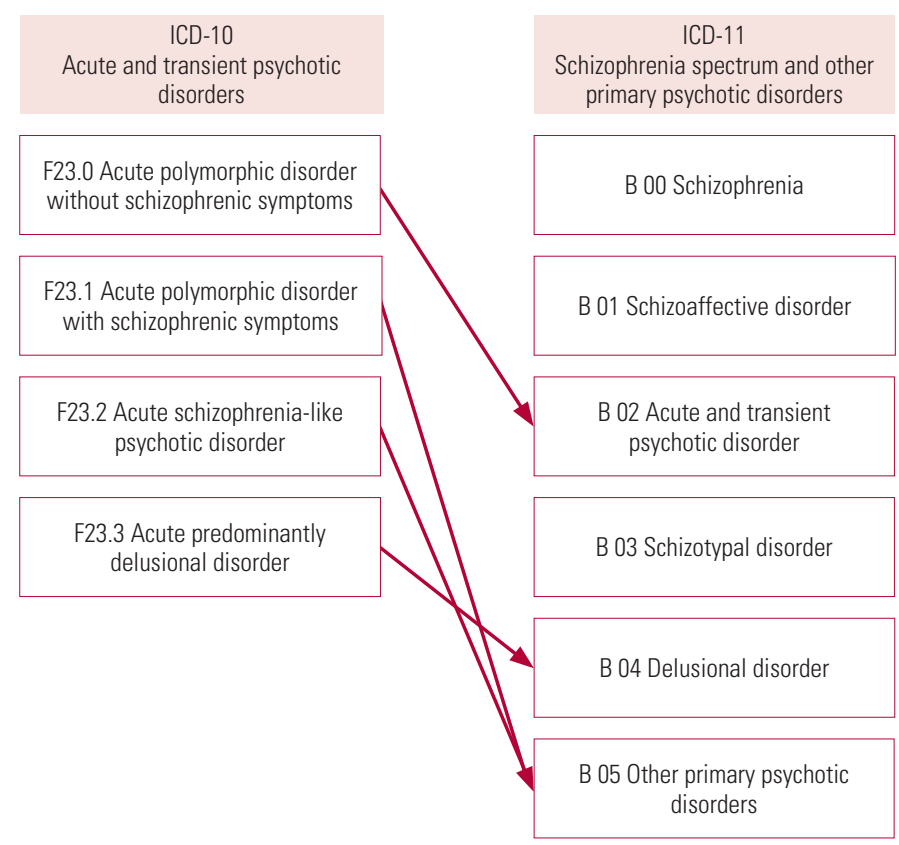

Proposed changes to ICD-10 F23 category 'acute and transient psychotic disorders' and the newly renamed section 'schizophrenia spectrum and other primary psychotic disorders' for ICD-11 (adapted from Gaebel 2012).

while their relationship to affective disorders deserves clarification (Castagnini 2013c, 2016).

\section{Clinical implications}

ATPDs have been excluded from major epidemiological surveys of first-episode psychosis, and hence the number of people likely to experience acute, florid onset of psychotic symptoms and early remission remains uncertain. The available evidence suggests that ATPDs are rare mental disorders and more often affect women in early to middle adulthood. It is not easy to identify cases in practice, as ATPDs' distinctive features, such as delusions, hallucinations and emotional turmoil, can change in both type and intensity daily or even faster, and some episodes culminate in impulsive or suicidal acts.

Apart from changes in auditory P300 amplitude, brain scan and cerebral blood flow associated with cycloid psychosis (Beckmann 2001), neither structural nor functional brain alterations have been observed in ATPDs. Yet there seems to be greater evidence of psychosocial factors, especially in low- and middle-income countries and migrant populations.

Further evidence indicates that ATPDs have little prognostic validity, as around half of patients developed either schizophrenia and related disorders or, to a lesser extent, affective disorders. While schizophrenic symptoms, young age at onset and male gender are more likely to be associated with subsequent transition to schizophrenia and/or schizoaffective disorders, the effect of acute onset, early remission and shifting polymorphic features on outcome of ATPDs has yet to be established.

Conditions such as the 'non-affective acute remitting psychoses' (Susser 1994) have an uneven geographical distribution, with a higher frequency in low- and middle-income countries, particularly in women, and are often associated with stress, fever or systemic infections and fewer negative symptoms than schizophrenia, but seldom fulfil the criteria for ATPDs (Mojtabai 2000; Nugent 2011). Transcultural studies suggest a parallel with the socioclinical conditions that characterised the early stages of industrialisation in 19th-century Europe, when bouffée délirante and reactive psychosis were described (Guinness 1992).

\section{Nosological implications}

Recently published papers have put the study of ATPDs on a new empirical footing and challenged the classification of ATPDs into different subtypes. The proposed revision for ICD-11 (Gaebel 2012) would introduce a major change by restricting the ATPD category to acute polymorphic psychotic disorder defined by criteria similar to those currently used and a duration shorter than 3 months. The remaining subtypes with schizophrenic and predominantly delusional symptoms would be redistributed into other categories of the newly renamed F2 section 'schizophrenia spectrum and other primary psychotic disorders' (Fig. 2). Such changes are expected to bring the ATPDs category closer to the 'non-affective acute remitting psychoses', which are reported to have typically 2-4 months' duration (Mojtabai 2000). Also under discussion is the proposal to add 'qualifiers' for symptoms, course, cognition and functional impairment in order to identify further distinctive features and provide useful information about patients. This reveals more about the technicalities of psychiatric diagnostics than about the disease itself, and it seems questionable whether polymorphic psychotic disorder may constitute a reliable diagnosis because of the lack of clearly defining features.

An alternative option, by analogy with the DSM5 category of brief psychotic disorder, would be to select the clinical features that lend themselves to easier assessment, such as acute onset, florid psychotic symptoms and short duration. Close overlap between the two diagnostic categories might have benefits for practice, research and the wider understanding of these conditions. 


\section{Conclusions}

Acute and transient psychoses have resisted specific description, and case identification has proved difficult. This argues against a clear demarcation of these conditions from schizophrenia and related disorders, but it is desirable that they are kept separated for both clinical practice and research.

\section{References}

Aadamsoo K, Saluveer E, Küünarpuu H, et al (2011) Diagnostic stability over 2 years in patients with acute and transient psychotic disorders. Nordic Journal of Psychiatry, 65: 381-8.

American Psychiatric Association (2013) Diagnostic and Statistical Manual of Mental Disorders (Fifth edn, DSM-5). APA.

Beckmann H, Franzek E (2001) Cycloid psychoses and their differentiation from affective and schizophrenic psychoses. In Contemporary Psychiatry (eds F Henn, N Sartorius, H Helmchen, et al): 387-98. Springer.

Björkenstam E, Björkenstam C, Hjern A, et al (2013) A five year diagnostic follow-up of 1840 patients after a first episode non-schizophrenia and non-affective psychosis. Schizophrenia Research, 150: 205-10.

Castagnini A, Berrios GE (2009) Acute and transient psychotic disorders (ICD-10 F23): a review from a European perspective. European Archives of Psychiatry and Clinical Neuroscience, 259: 433-43.

Castagnini A, Berrios GE (2011) Acute transient psychoses and their differentiation from schizophrenia. Current Psychiatry Reviews, 7: 248-55.

Castagnini A, Foldager $L$ (2013a) Variations in incidence and age of onset of acute and transient psychotic disorders. Social Psychiatry and Psychiatric Epidemiology, 48: 1917-23.

Castagnini A, Foldager L, Bertelsen A (2013b) Excess mortality of acute and transient psychotic disorders: comparison with bipolar affective disorder and schizophrenia. Acta Psychiatrica Scandinavica, 128: 370-5.

Castagnini AC, Laursen TM, Mortensen PB, et al (2013c) Family psychiatric morbidity of acute and transient psychotic disorders and their relationship to schizophrenia and bipolar disorder. Psychological Medicine, 43: 2369-75.

Castagnini A, Foldager L, Bertelsen A (2013d) Long-term stability of acute and transient psychotic disorders. Australian and New Zealand Journal of Psychiatry, 47: 59-64.

Castagnini A, Foldager L (2014) Epidemiology, course and outcome of acute and transient psychotic disorders: implications for ICD-11. Psychopathology, 43: 202-6.

Castagnini A, Munk-Jørgensen P, Bertelsen A (2016) Short-term course and outcome of acute and transient psychotic disorders: differences from other types of psychosis with acute onset. International Journal of Social Psychiatry, 62: 51-6.

Chakraborty R, Chatterjee A, Choudhary S, et al (2007) Life events in acute and transient psychosis: a comparison with mania. German Journal of Psychiatry, 10: 36-40.

Cooper JE, Jablensky A, Sartorius N (1990) WHO Collaborative studies on acute psychoses using the SCAAPS schedule. In Psychiatry: A World Perspective (eds CN Stefanis, AD Rabavilas, CR Soldatos): 185-92. Excerpta Medica.

Cutting J (1990) Relationship between cycloid psychosis and typical affective psychosis. Psychopathology, 23: 212-9.

Das SK, Malhotra S, Basu D (1999) Family study of acute and transient psychotic disorders: comparison with schizophrenia. Social Psychiatry and Psychiatric Epidemiology, 34: 328-32.

Das SK, Malhotra S, Basu D, et al (2001) Testing the stress-vulnerability hypothesis in ICD-10-diagnosed acute and transient psychotic disorders. Acta Psychiatrica Scandinavica 104: 56-58.

Ey H (1954) Les bouffées délirantes et les psychoses hallucinatoires aiguës. Étude n. 23. In Ėtudes Psychiatriques (vol III): 203-324. Desclée de Brouwer.
Esan 0, Fawole OL (2014) Acute and transient psychotic disorder in a developing country. International Journal of Social Psychiatry, 60: 442-8.

Gaebel W, Zielasek J, Cleveland HR (2012) Classifying psychosis challenges and opportunities. International Review of Psychiatry, 24: 538-48.

Garrabé J, Cousin FR (2012) Acute and transient psychotic disorders. In New Oxford Textbook of Psychiatry (eds M Gelder, JJ Lopez-lbor, NC Andreasen, et al): 644-9. Oxford University Press.

Guinness EA (1992) Patterns of mental illness in the early stages of urbanisation. British Journal of Psychiatry, 160 (suppl 4): s4-41.

Hatotani N (1996) The concept of 'atypical psychoses': special reference to its development in Japan. Psychiatry and Clinical Neuroscience, 50: $1-10$

International Early Psychosis Association Writing Group (2005) International clinical practical guidelines for early psychosis. British Journal of Psychiatry, 187 (suppl 48): s120-4.

Jabs B, Krause U, Althaus G, et al (2004) Differences in quality of life and course of illness between cycloid psychoses and schizophrenia: a comparative study. World Journal Biological Psychiatry, 5: 136-42.

Jaspers K (1913) Allgemeine Psychopathologie. Springer.

Jørgensen P, Bennedsen B, Christensen J, et al (1997) Acute and transient psychotic disorder: a 1-year follow-up study. Acta Psychiatrica Scandinavica, 96: 150-4.

Kanazawa T, Ikeda M, Glatt SJ, et al (2013) Genome-wide association study of atypical psychosis. American Journal of Medical Genetics: Part B Neuropsychiatric Genetics, 162B: 679-86.

Kasanin J (1933) The acute schizoaffective psychoses. American Journal of Psychiatry, 13: 97-126.

Kleist K (1928) Über zykloide und epileptoide Psychosen und über die Frage der Degenerationspsychosen. Schweizer Archiv für Neurologie und Psychiatrie, 23: 3-37. Translated into English (1974) as 'Cycloid, paranoid and epileptoid psychoses and the problem of degenerative psychoses'. In Themes and Variations in European Psychiatry (eds RS Hirsh, M Shepherd): 297-331. Wright.

Kingston T, Scully PJ, Browne DJ, et al (2013) Diagnostic trajectory, interplay and convergence/divergence across all 12 DSM-IV psychotic diagnoses: 6-year follow-up of the Cavan-Monaghan First Episode Psychosis Study (CAMFEPS). Psychological Medicine, 43: 2523-33.

Kørner A, Lopez AG, Andersen PK, et al (2009) Acute and transient psychosis in old age and the subsequent risk of dementia: a nationwide register-based study. Geriatrics and Gerontology International, 9: 62-8.

Korver-Nieberg N, Quee PJ, Boss HB, et al (2011) The validity of the DSMIV diagnostic classification system of non-affective psychoses. Australian and New Zealand Journal of Psychiatry, 45: 1061-68.

Kraepelin E (1896) Psychiatrie. Barth.

Labhardt F (1963) Die schizophrenieähnlichen Emotionspsychosen. Gesamtgebiet Neurologie Psychiatrie (Heft 102). Springer Verlag.

Langfeldt G (1939) The Schizophreniform States. Munksgaard.

Lau PWL, Cheng JGY, Chow DLY, et al (2009) Acute psychotic disorders in foreign domestic workers in Hong Kong: a pilot study. International Journal of Social Psychiatry, 55: 569-76.

Leonhard K (1957) Aufteilung der endogenen Psychosen. AkademieVerlag. Translated into Englis (1979) as The Classification of Endogenous Psychoses. Irvington

Lewis A (1972) Psychogenic: a word and its mutations. Psychological Medicine, 2: 209-15.

Linden SC, Harris M, Whitaker C, et al (2009) Religion and psychosis: the effect of the Welsh religious revival in 1904-1905. Psychological Medicine, 40: 1317-23.

Magnan V (1887) Leçon Cliniques sur les Maladies Mentales. Delahaye \& Lecrosnier.

Marneros A, Pillmann F (2004) Acute and Transient Psychoses. Cambridge University Press.

\section{MCO answers}

1 b $\quad 2$ e $\quad 3$ a $\quad 4$ b $\quad 5 d$ 
Möller HJ, Jäger M, Riedel M, et al (2011) The Munich 15-year followup study (MUFSSAD) on first-hospitalized patients with schizophrenic or affective disorders: assessment, course, type and time stability of diagnostic classification. European Psychiatry, 26: 231-43.

Mojtabai R, Varma VK, Susser E (2000) Duration of remitting psychoses with acute onset: implications for ICD-10. British Journal of Psychiatry, 176: $576-80$

National Institute for Health and Care Excellence (2014) Psychosis and Schizophrenia in Adults: Treatment and Management (NICE Clinical Guideline 178). NICE.

Nugent KL, Paksarian D, Mojtabai R (2011) Nonaffective acute remitting psychoses: uncertainties on the way to DSM-V and ICD-11. Current Psychiatry Reports, 13: 203-10.

Parrett NS, Mason OJ (2010) Refugees and psychosis: a review of the literature. Psychosis: Psychological, Social and Integrative Approaches, 2: $111-21$

Peralta V, Cuesta MJ (2003) Cycloid psychosis: a clinical and nosological study. Psychological Medicine, 33: 443-53.

Perris C, Brockington IF (1981) Cycloid psychoses and their relation to the major psychoses. In Biological Psychiatry (eds C Perris, G Struwe, B Jansson): 447-50. Elsevier.

Pull MC, Pull CB, Pichot $P$ (1987) Des critères empiriques français per les psychoses. II: consensus des psychiatres français et definitions provisoires. Encéphale, 13: 53-7.

Queirazza F, Semple DM, Lawrie SM (2014) Transition to schizophrenia in acute and transient psychotic disorders. British Journal of Psychiatry, 204: 299-305

Rusaka M, Rancāns E (2014) First-episode acute and transient psychotic disorder in Latvia: a 6 years follow-up study. Nordic Journal of Psychiatry, 68: 24-9.

Saha S, Chant D, McGrath J (2007) A systematic review of mortality in schizophrenia: is the differential mortality gap worsening over time? Archives of General Psychiatry, 64: 1123-31.

Salvatore P, Baldessarini RJ, Tohen M, et al (2011) McLean-Harvard International First-Episode Project: two-year stability of ICD-10 diagnoses in 500 first-episode psychotic disorder patients. Journal of Clinical Psychiatry, 72: 183-93.
Sartorius N, Üstun TB, Korten A, et al (1995) Progress towards achieving a common language in psychiatry, II: Results from the international field trials of the ICD-10 diagnostic criteria for research for mental and behavioural disorders. American Journal of Psychiatry, 152: 1427-37.

Schneider K (1959) Klinische Psychopathologie, Aufl 5. Thieme. Translated into English (1967) as Clinical Psychopathology. Grune \& Stratton.

Singh SP, Burns T, Amin S, et al (2004) Acute and transient psychotic disorders: precursors, epidemiology, course and outcome. British Journal of Psychiatry, 185: 452-9.

Strömgren E (1974) Psychogenic psychoses. In Themes and Variations in European Psychiatry (eds HS Hirsh, M Shepherd): 97-117. Wright.

Susser E, Wanderling J (1994) Epidemiology of nonaffective acute remitting psychosis vs schizophrenia: sex and sociocultural setting. Archives of General Psychiatry, 51: 294-301.

Ungvari GA, Mullen PE (1997) Reactive psychoses. In Troublesome Disguises: Underdiagnosed Psychiatric Disorders (eds D Bhugra, A Munro): 52-90. Blackwell.

Vaillant GE (1962) The prediction of recovery in schizophrenia. Journal of Nervous Mental Disease, 135: 534-43.

van der Heijden FMMA, Tuinier S, Kahn RS, et al (2004) Nonschizophrenic psychotic disorders: the case of cycloid psychoses. Psychopathology, 37 : 161-7.

Weibel H, Metzger JY (2005) Psychoses délirantes aiguës. EMC Psychiatrie, 21: 40-61.

Wimmer A (1916) Psykogene Sindssygdomsformer. In Sct. Hans Hospital 1816-1915 Jubilaeums-skrifts: 85-216. Copenhagen. Translated into English (2003) as Psychogenic Psychoses (trans \& ed J Shioldann). Adelaide Academic Press.

World Health Organization (1992) The ICD-10 Classification of Mental and Behavioural Disorders: Clinical Descriptions and Diagnostic Guidelines. WHO

Wunderink L, Nieboer RM, Wiersma D, et al (2013) Recovery in remitted first-episode psychosis at 7 years of follow-up of an early dose reduction/ discontinuation or maintenance treatment strategy: long-term follow-up of a 2-year randomized clinical trial. JAMA Psychiatry, 70: 913-20.

\section{MCQs}

Select the single best option for each question stem

1 Current diagnosis of acute and transient psychosis is based on:

a aetiology

b symptoms

c prognosis

d reliability

e validity.

2 Pathognomonic features of acute and transient psychoses include:

a Schneider's first-rank symptoms of schizophrenia

b shifting polymorphic symptoms

c negative symptoms

d confusion or perplexity

e none of the above.
3 The frequency of acute and transient psychoses per 100000 population is estimated at:

a $1-10$

b $10-20$

c 20-50

d $50-100$

e $>100$.

4 Factors associated with favourable outcome in acute and transient psychoses include:

a onset within 4 weeks

b female gender

c precipitating stress

$\mathrm{d}$ affective symptoms

e family history of psychosis.

\author{
5 Treatment and management of acute and \\ transient psychoses is based on: \\ a specific guidelines \\ b NICE guidelines for psychosis and schizophrenia \\ c first-episode psychosis guidelines \\ d clinical experience \\ e expert consensus.
}

